\title{
Catalytic Enantioselective Fluorination of $\alpha$-Cyano Esters by Phase-Transfer Catalysis Using Chiral Quaternary Ammonium Salts
}

\author{
Eun Joo Park, Hye Ran Kim, Chang Ung Joung, and Dae Young Kim" \\ Department of Chemistry, Soonchunhang University, Asan, P.O. Box 97. Chungnam 336-600, Korea \\ Received March 9. 2004
}

Key Words : Phase-transfer catalyst, Fluorination, Chiral ammonium salt, $\Lambda$ symmetric reactions

The chemistry of bioactive organofluorine compounds is a rapidly developing area of research because of their importance in biochemical and medicinal application.' Chiral organofluorine compounds are interesting and important materials with uses in analytical, biological and medicinal chemistry. ${ }^{2}$ In particular, chiral acyclic monofluoro compounds have many applications such as chiral building blocks, ${ }^{3}$ chiral derivatization reagents, ${ }^{1}$ and synthetic intermediates for organic synthesis. ${ }^{5}$ Recent advances in synthetic methodology of electrophilic enantioselective fluorinations by Shibata, Cahard, Togni, Sodeoka and us have led to significant improvements over the past few years, ${ }^{6.7}$ A number of enantioselective fluorination of $\beta$-keto esters has been achieved by reagent-controlled enantioselective fluorination. ${ }^{8}$ alkaloid/Selectrofluor combination, ${ }^{6 a-6 c}$ and catalytic enantioselective fluorination using chiral titanium or palladium complex. ${ }^{60.65}$ However, few examples have been demonstrated to date for enantioselective fluorination of $\alpha$-cyano acetates, and only enantioselective fluorination using cinchona alkaloid/Selectrofluor combination has proved to be promising as an alternate strategy. The total absence of an efficient catalytic reaction for enantioselective fluorination of $\alpha$-cyano acetates prompted us to embark in a study aimed at the development of such a reaction.

As part of our research program related to the development of effective cinchona alkaloid-derived phase-transfer catalysts," we report the catalytic enantioselective florination of $\beta$-keto esters promoted by a cinchonine-derived quaternary ammonium salts as a phase-transfer catalyst. ${ }^{7}$ In this paper. we wish to report the catalytic entioselective electrophilic fluorination of $\alpha$-cyano acetates using the cinchona alkaloid derived quaternary ainmonium salts 4 .

[o determine suitable reaction conditions for the catalytic enantioselective electrophilic fluorination of $\alpha$-cyano acetates, we initially investigated the reaction system with methyl $\alpha$ cyano phenylacetate 1a using $N$-fluorobenzenesulfonimide 2 as the electrophilic fluorinating agent in the presence of 10 mol\% of catalyst 4 in toluene at room temperature (lable 1).

The effects of base has been investigated first, and as shown in Table 1 , the compound (-)-3a was always formed under the various reaction conditions as the excessive enantiomer, which should be the case because all of the

Corresponding Author. Iel: $-82-41-530-1244$ : fax: $-82-41-530-$ 1247: c-mail: dyoungiàsch.ac.kr
Table 1. Influence of phase-Iranster calalysts. bases. and ester group of $\alpha$-cyano actate 1

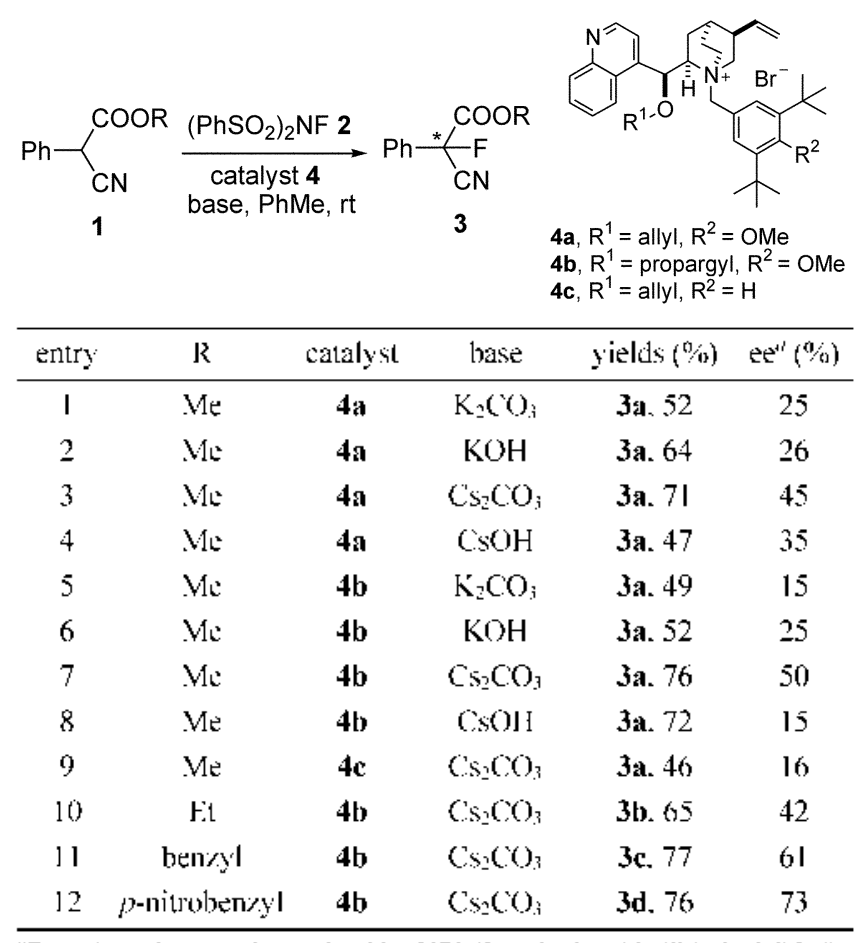

"Enmtiopurity was determined by IIPLC andysis with Chiralcel O.I (for $\mathbf{3} \mathbf{a}$ and $\mathbf{3 b}$ ) or (Chiralpak AD) (for $\mathbf{3 c}$ and $\mathbf{3} \mathbf{d}$ ) columns.

catalysts used possess the same chirality. Catalyst $\mathbf{4 b}$ having $O$-propargyl group showed higher catalytic efficiency than others in terms of yields and enantioselectivity in the presence of $\mathrm{Cs}_{2} \mathrm{CO}_{3}$ as a base (entry 7). It has been also found that $\mathrm{Cs}_{2} \mathrm{CO}_{3}$ was the more effective base in this reaction than others such as $\mathrm{CsOH}, \mathrm{K}_{2} \mathrm{CO}_{3}$, and $\mathrm{KOH}$. Furthermore, we also investigated the effect of ester group on enantioselectivity (entries 7 and 10-12). The best results have been obtained with $p$-nitrobenzyl ester of substrate $\mathbf{3 d}$ ( $73 \%$ ee). As we expected, the reaction was proceeded but the enantioselectivity was $0 \%$ ee in the case without chiral phase-transfer catalyst. Interesting is solvent effect, i.e. the reagent-controlled and catalytic enantioselective fluorination procedures were generally proceeded more efficiently in polar solvents such as acetonitrile. ${ }^{\text {6il-60 }}$ In contrast. this reaction was complete within 30 min in nompolar solvent at room temperature. ${ }^{10}$ to examine the generality of the 
Table 2. Catalytic mantioselective tluorination of 1 with phasctransfèr catalyst $\mathbf{4 h}$

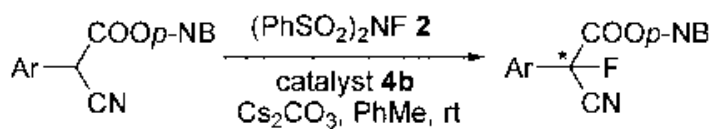

1 3

(1\%)

"Enantiopurity was delermined by IIPLC analysis with a Chiralpak $A D$ columin.

enantioselective fluorination using chiral phase-transfer catalyst $\mathbf{4 b}$, we studied the fluorination of $\alpha$-cyano esters $1 \mathbf{d}$ Ih (lable 2). The flworination reaction was carried out at room temperature. As can be seen by the results summarized in Table 2, all of the corresponding $\alpha$-cyano $\alpha$-fluoro esters 3d-3h were obtained in high yields with moderate selectivities.

We have developed a mild and practical catalytic enantioselective fluorination using a chiral phase-transfer catalyst with $N$-fluorobenzenesulfonimide. $\alpha$-Cyano acetate derivatives were fluorinated enantioselectively to give the corresponding $\alpha$-fluoro compounds in high yields with good to moderate enantiomeric excess under phase-transfer conditions. We are curtently involved in the extension of this convenient fluorination process to other enolizable substrates and are investigating the applicability of phasetransfer catalysts to other asymmetric phase-transfer processes.

\section{References}

1. Hudlicky: M.: Pavalath. A. E. Chemistry of Organic Fhorine Contpoumds /: American Chemical Socisty. Washington DC. 1995

2. Iliyame, T.: Kanie, K.: Kusumoto, T.: Morizawa Y.: Shimizu, M. Organofltorine Conponds: Chemistry and Applicaitons: SpringerVerlag: Berlin. 2000 .

3. Bravo. P.: Resnati. G. Fetratedron: Asymmetry 1990. /. 661-692.

4. (a) Takeuchi. Y.: Konishi. M.: Hori. H.: Takehashi. T.: Konctani. T.: Kirk, K. 1., Chem. Conmmen. 1998. 365-366, (b) Takeuchi. Y.: Konishi, M.: Ifori. II: Takehassi, T.: Kometanji, T.: Kirk. K. I. Enontiomer 1999. f. 339. (c) Takeuchi, Y: ['ukushimat $\mathrm{A}$ : Janaka. Y.: Takeuchi. Y.: Kabuto. K.: Kabulo. C. Chen. Commun. 2000. 787-788. (d) Fugiwara. T: Sasaki. M.: Onata. K.: Kabuto. C.: Kabuto. K.: Takcuchi. Y. Tetrahedon: Asymmetry 2004. I5. $555-563$.

5. Kusumoto. T.: Hiyama T: In Frantioconfolled Symthess of Fhoro-organic Compounds: Soloslonok, V. A. [ids.a John Wiley \& Sons: Chichester. 1999: pp 536-556.

6. (a) Shibata. N.: Suzuki. E.: Takouchi. Y. J. Am. Chem. Soc 2000. 122. 10728-10729. (b) Shibata. N.: Suzuki. E.: Asahi. T.: Shiro. M. J. Am. Chem Soc. 2001. /23.7001-7009, (c) Shibata V.: Ishimaru T: Suruki. F.: Kirk. K. L. J. Org. Chem. 2003. 68 . 2494-2497. (d) Cahard. D.: Nudouard. C.: Plaquevent. J.-(... Joupel. L.: Roques. V. Tetrathedron Lett. 2001. +2. 1867-1869. (e) Baudequit. C.: Loubassou. I.-F.: Plaquevent. T.-C.: Cahard. D. . . Fhorin (Tem. 2003. /22. 189-193. (f) Hintermann. L.: Togni. A. Angew: Chem, Int Ed. Engl, 2000 39. 4359-4362, (g) Ilamashimat Y.: Yagi. K.: Takano. H.: lamas. L.: Sodeoka. M. J. Am. Chen. Soc. 2002. /2t. 14530-1453I.

7. Kim. D. Y.: I'arh. E. I. Org. Lett. 2002. f. 545-547.

8. (a) Differding. E.: Lang. R. W. Tethedredron Lett. 1988. 2\%. 60876090. (b) Davis. F. A.: Zhou. P.: Murphy. C. K.: Sundarababu. G.: Qi. H1.: Przeslawshi. R. M.: Chen. B.-C: Carroll. P. J. J. Org. (Them. 1998. 63. 227.-2280. (c) Takeuchi. Y.: Suzuki. T.: Saloh. A.: Shiragami. I.: Shibata $N$. J. Org. (hem. 1999, 64.5708-57II.

9. (a) Kim. D. Y.: Huh. S. C.: Kim. S. M. Tetrettedron lett 2001. 42. 6299-6301. (b) Kim. D. Y.: Huth. S. C. Tetrahedron 2001. 57. 8933-8938. (c) Kim. D. Y.: Choj. Y. I.: Park. H. Y.: Joung. C. U.: Koh. K. 0.: Mang. J. Y.: Jung. K. Y. Stmh. Conmma 2003. 33. 435-443. (d) Kim. D. Y.: Kim. S. M.: Kol. K. O.: Mang. J. Y.: L.ee. K. Bull. Korean (hem. Soc. 2003. 24. 1425-1426. (e) Park. B. S.: Kim. D. Y.: Rosenthal. P. J.: Huth. \$. C.: Lee. B. I.: Park. \$. M.: Kim. J. E.: Kim. M. H.: Huh. T. L.: Choi. Y. J.: Suh. K. H.: Choi. W. S.: Lee. S. E. Bioorg. Wed Chem. Lett. 2002. 12. 13511.355. (f) Kim, D. Y: H luh. S. C. Bull. Sorean Chem. Soc. 2004. 25. 347-348. (g) Park. J:. I.: Kim. V. [1.: Kim. D. Y. J. Org. (hem. 2004. 69. $6897-6899$.

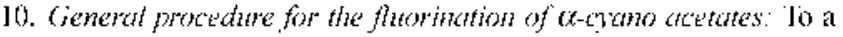
stirred solution of $\alpha$-clano acctate $(0.3 \mathrm{mmol}) . \mathrm{Cs}_{2} \mathrm{CO}_{3}(33 \mathrm{mg}$. $0.1 \mathrm{mmol})$ in toluene $(3 \mathrm{~mL}$ ) was added chiral cinchonium salt $\mathbf{4 h}$ (19) $\mathrm{mg}, 0.03 \mathrm{mmol}$ ) at room temperature. Reaction mixture was stimed for 1 h at room temperature. A-lluorobenzenesulfonimide (95 me. 0.3 mmole) was added slow ly for 1-2 min. Alter 30 min. the mixture was diluted with water $(10 \mathrm{~mL})$ and extracted with ethyl acetate $(2 \backslash 10 \mathrm{~mL})$. The combined orgatic layers were dricd over $\mathrm{MgSO}_{4}$. filtered. concentrated. and puritied by flash chromategraphy (silica gel, ethyl acetate: hexane $=1: 8$ ) to athord the $\alpha$-cyano $\alpha$-fluoro acelate. 